\title{
Effect of Dietary Regimes on Development of Digestive System of Stinging Catfish, Heteropneustes fossilis (Bloch) Larvae
}

\author{
Aditya Kumar ${ }^{1,2}$, P. K. Pradhan ${ }^{1 *}$, N. K. Chadha ${ }^{2}$, V. Mohindra ${ }^{1}$, \\ V. K. Tiwari ${ }^{2}$ and N. Sood ${ }^{1}$ \\ ${ }^{1}$ ICAR-National Bureau of Fish Genetic Resources, Canal Ring Road, Dilkusha, \\ Lucknow - 226002, Uttar Pradesh, India \\ ${ }^{2}$ ICAR-Central Institute of Fisheries Education, Panch Marg, Off Yari Road, Andheri (W), \\ Mumbai - 400 061, Maharashtra, India \\ *Corresponding author
}

\section{A B S T R A C T}

Keywords

Dietary regimes;

Survival; Growth;

Digestive system;

Heteropneustes fossilis

Article Info

Accepted:

04 July 2018

Available Online:

10 August 2018
In the present study, effects of different dietary regimes on development of digestive system in stinging catfish, Heteropneustes fossilis (Bloch) larvae were investigated. Seven different dietary regimes (DR), varying in food type (Artemia nauplii, zooplankton or microdiet) and their combinations, were evaluated in triplicate. With regard to effect of different dietary regimes on the morphogenesis of the digestive system, it was observed that weaning had no effect on the timing of development of the digestive organs. However, at the end of study ( $22 \mathrm{dph}$ ), no differences were observed in the development of digestive system among different dietary regime regardless of the weaning strategies investigated. Therefore, it can be concluded that it is feasible to rear stinging catfish larvae without dependence upon artemia nauplii, and the larvae may be weaned to microdiets after $7 \mathrm{dph}$. This information would be very helpful to improve the larval rearing techniques for this important candidate catfish species in the Asian countries.

\section{Introduction}

Heteropneustes fossilis (Bloch), also known as stinging catfish is one of the economically and therapeutically important fish species in many Asian countries particularly, in India, Thailand, Bangladesh, Pakistan, Nepal, Sri Lanka, Myanmar, Indonesia, and Cambodia (Burgess, 1989; Akand et al., 1991). The species is highly preferred because of its delicious taste, nutritional and medicinal properties and high market price (Chakraborty and Nur, 2012). Moreover, this catfish can be cultured at high stocking density in wastewater aquaculture system. Because of these characteristics, the species has high market demand and economic value (US\$ 6$8 / \mathrm{kg}$ ) in these countries. Importantlly, $H$. fossilis has been prioritized as one of the fish species for aquaculture and considered as a candidate species for the diversification of freshwater aquaculture in India (NBFGR, 2011). However, in the country, the aquaculture of this species is not commercially successful due to unavailability of quality seed. High mortality rates during larval rearing and scant knowledge of their feeding strategies are major constraints of farming 
success. Further, wild seed collection is almost negligible due to habitat alterations (Vijayakumar et al., 1998). Therefore, it is the need of time to develop effective, reliable and efficient larval rearing techniques and dietary regimes to ensure consistent production of quality seeds to meet the demand.

In fish larviculture, zooplankton and artemia are usually provided as feed during first feeding. However, low production and high price of live feed are major bottlenecks for their production on commercial level (PersonLe Ruyet et al., 1993). Moreover, mass culture of live feed requires high costs and is labour intensive along with the highly variable nutritional value of live feeds (Person-le Ruyet et al., 1993; Cahu \& Zambonino Infante, 2001; Langdon, 2003). Therefore, formulated microdiets could be used for the replacement of live food. However, the use of formulated microdiets immediately after hatching, can cause poor survival and growth of larva due to inappropriate development of digestive system (Jones et al., 1993; Person-Le Ruyet et al., 1993; Watanabe and Kiron, 1994). Furthermore, the early introduction of formulated diet al.,one has found limited success in freshwater species (Koven et al., 2001). There are no universal weaning strategies for fish larvae because of difference in timing of development, maturation and functionality of digestive system (Cahu and Zambonino Infante, 200; Lazo et al., 2011). Consequently, variability in timing of organ development and associated physiological functions affected due to difference in reproductive guilds. It is also affected because of environmental rearing conditions, especially water temperature. In this paper, authors have investigated how different dietary treatments affected the digestive tract development in $H$. fossilis under controlled laboratory conditions. The new information generated in the present study would be helpful in improving the understanding of feeding strategies and actual larval rearing techniques for $H$. fossilis, one of the most popular and promising catfish for diversification of freshwater aquaculture in Asia.

\section{Materials and Methods}

\section{Source of larvae}

The experimental trials were conducted at indoor hatchery of fish genetic resource centre of ICAR-NBFGR, Lucknow, India. Larvae were produced by induced spawning of sexually mature fish (male \& female) of $H$. fossilis. Briefly, both female (145-169 g) and male (87-95 g) stinging catfish were injected intramuscularly with synthetic hormone Ovarim $^{\circledR}$, (Congruent Pharmachem Pvt. Ltd. Mumbai, India) at the rate of $1.0 \mathrm{ml}$ and 0.5 $\mathrm{ml} \mathrm{kg}^{-1}$ body weight, BW respectively. Stripping of females, sperm collection and fertilization were done following the protocol described by Puvaneswari et al., (2009). The fertilized eggs were subsequently incubated in Fiber Reinforced Plastic (FRP) tray incubators at $28.0 \pm 1.1{ }^{\circ} \mathrm{C}$ with continuous water flow. Newly hatched larvae were kept in the incubators until the age of $1 \mathrm{dph}$.

\section{Experimental procedures and feeding regimes}

A total of 1260 larvae were randomly selected for the experiment. Sixty larvae (1 dph, 0.2 $\mathrm{mg}$ ) were stocked in 21 circular FRP tanks containing $30 \mathrm{~L}$ water each (stocked at a density of 2 larva $1^{-1}$ ), and the feeding experiment started at $2 \mathrm{dph}$. Aeration was given in each tank to provide dissolved oxygen and help in a homogeneous distribution of feed throughout the water column. Water quality parameters such as water temperature, dissolved oxygen and $\mathrm{pH}$ values were maintained at $28.0-29.1{ }^{\circ} \mathrm{C}, 6-8$ $\mathrm{mg} \mathrm{l}^{-1}$ and 6.8-7.6, respectively during the experiment period. 
Seven different dietary regimes varying in food type (Artemia nauplii, zooplankton or microdiet) and duration were evaluated in triplicate. The age at which different food items were given to larvae, were intended to find out the most convenient dietary regime and weaning strategy for stinging catfish larvae (Fig. 1). Therefore, larvae were reared under the following dietary regimes (DR) from the onset of the exogenous feeding at 2 dph until 22 dph: DR-A, larvae fed with nonenriched Artemia nauplii (OSI PRO 80 ${ }^{\mathrm{TM}}$, Ocean Star International, Inc., USA) from 2 to 22 dph; DR-B, larvae fed with mixed zooplankton (Copepods, Cyclops and cladocerans) collected from a fish pond from 2 to $22 \mathrm{dph}$; DR-C, larvae fed with a commercial microdiet (Micro Elite 50, Lucky Star®, Taiwan) from 2 to $22 \mathrm{dph}$; DR-D, larvae fed with non-enriched Artemia nauplii from 2 to $8 \mathrm{dph}$, zooplankton from 6 to $12 \mathrm{dph}$ and the microdiet from 10 to $22 \mathrm{dph}$; DR-E, larvae fed with zooplankton from 2 to $7 \mathrm{dph}$ and the microdiet from 5 to $22 \mathrm{dph}$; DR-F, larvae fed with zooplankton from 2 to $10 \mathrm{dph}$ and the microdiet from 7 to $22 \mathrm{dph}$; DR-G, larvae fed with zooplankton from 2 to $12 \mathrm{dph}$ and the microdiet between 9 and $22 \mathrm{dph}$. In all the treatments, larvae were fed with different diets to satiation three times per day (08:00, 12:00 and 16:00 h) for 20 days (Mollah and Tan, 1982).

The feeding protocol in dietary regimes $\mathrm{D}-\mathrm{G}$ composed of decreasing the frequency of live feed (Artemia nauplii and zooplankton) and increasing the frequency of formulated diet feeding $(4 / 0,3 / 1,2 / 2,1 / 3,0 / 4)$ within 2 consecutive days. The feed waste and faecal residues were siphoned out daily before first feeding provided at 08:00 $\mathrm{h}$ and $30 \%$ water exchange was done in all the tanks.

\section{Larval sampling for histological procedures}

At each sampling day, 5 larvae from each experimental tanks $(\mathrm{n}=15$ per dietary treatment) were randomly sampled and larvae were fixed in $10 \%$ buffered formalin $(\mathrm{pH}=$ $7.0)$ at $7,12,17$ and $22 \mathrm{dph}$. Then, larvae were dehydrated in a graded series of ethanol, cleaned in chloroform, embedded in paraffin, cut into serial sagittal sections (3-4 $\mu \mathrm{m}$ thick), mounted on glass slide and air dried. Sections were deparaffinized with graded series of xylene and stained by Harris' Hematoxylin and Eosin (HE) procedure for general histomorphological observations. The development of the digestive system in stinging catfish larvae was compared among different dietary regimes according to Pradhan et al., (2014). Histological images were obtained by an Olympus (BX 53, Japan) light microscope.

\section{Results and Discussion}

Histological assessment of condition of larvae in early development stages is one of the most accurate indicator of nutritional status (Ferron and Leggett, 1994). Further, histological observations can be made from several tissues from a single specimen, which respond at different rates to food deprivation and diets, enabling a more precise description of the nutritional state of an individual (Gisbert et al., 2008). The development of the digestive tract in stinging catfish larvae have been already studied through histological description under standard rearing condition (unpublished data). However, in this paper authors have tried to understand the effect of different dietary regimes and weaning strategies on the histological differentiation of different parts of the digestive tract in stinging catfish larvae.

In the present study, in all the dietary regimes, the stomach was differentiated at $7 \mathrm{dph}$ (Fig. $1 \mathrm{~A}, \mathrm{C})$, however, in the case of dietary regimes DR-A and DR-D, stomach had more number of gastric glands and thicker gastric mucosal layer compared to other dietary regimes. On the other hand, in the rest of the 
dietary regimes, stomach had lesser number of gastric glands and thinner gastric mucosal layer and stomach of larval group fed with DR-C had lowest growth (Fig. 1B).

At $12 \mathrm{dph}$ and $17 \mathrm{dph}$, although the development was more advanced as compared to the previous sampling, the pattern of development in different dietary regimes was similar to $7 \mathrm{dph}$. At $22 \mathrm{dph}$, stomach development was almost similar among all dietary regimes (Fig. 1D). Similar to the present findings, Pradhan et al., (2014) reported that $O$. bimaculatus fed with microdiet showed retardation in the development of stomach in terms of number of gastric glands and gastric mucosal layer. However, authors have reported that at the end of the experimental period of 15 days, no difference in stomach development was observed between different dietary regimes.

Development of a functional stomach associated with the production of $\mathrm{HCl}$ and pepsin by gastric glands is considered as a crucial event for enabling young fish to digest compound diets (Zambonino-Infante et al., 2008; Rønnestad et al., 2013). In $C$. gariepinus, it has been reported that although larvae were able to be reared on microdiets from the onset of exogenous feeding, their growth rates were not comparable to those fed live food until their stomach became functional (Verreth and van Tongeren 1989; Verreth et al., 1992).

Therefore, the larval period in terms of nutrition ends with the completion of a functional stomach (Segner et al., 1993), and consequently, the stomach differentiation is considered as a decisive event in the nutritional physiology of larvae and could be used as an external marker for the start of weaning (Verreth et al., 1992; Senger et al., 1993).

At $7 \mathrm{dph}$, the intestine of stinging catfish larvae showed the similar pattern in all the dietary regime and no lipid accumulation were observed along larval development regardless of the dietary regime (Fig. 1E, F). The complexity of the intestinal morphology in fish varies with age and is also influenced by the quantity and quality of the feed (Gisbert et al., 2004, 2008; Rønnestad et al., 2013). It is generally accepted that the intestine is the major site for lipid absorption and larvae fed high levels of neutral lipids show intracellular and intercellular accumulation of fat in the intestine, while fish fed with low/moderate levels of lipids shows normal appearance and organization. Studies on the intestinal morphology of larvae have been conducted in various species of catfish, such as $O$. bimaculatus (Pradhan et al., 2014), $P$. punctifer (Gisbert et al., 2014), R. quelen (Silveira et al., 2013) and C. gariepinus (Verreth et al., 1992), showing that the intestinal morphology affects the digestibility and absorption of nutrients (Khojasteh, 2012). In European sea bass larvae, it has been reported that differences in lipid absorption and accumulation in the intestinal mucosa are influenced by dietary lipid levels (Gisbert et al., 2005). In the present study, in all the dietary regimes, intestinal mucosa had normal appearance and organization and no differences were observed in the deposition of lipids in the intestine between different dietary regimes. However, in contrast to the present findings in $O$. bimaculatus, larvae fed with artemia had led to higher accumulation of fat deposits in the intestine. In fish larvae, lipid droplets are not considered as part of the endoplasmic reticulum of Golgi apparatus of enterocytes and in many cases, they do not appear to be enclosed by any membrane.

This has led to the suggestion that intestinal lipid inclusions are a temporary storage form of re-esterified fatty acids in cases when the rate of lipid absorption exceeds the rate of lipoprotein synthesis (Sheridan, 1988), or because an inability to metabolise lipids 
(Kjørsvik et al., 1991). Therefore, it may be assumed that the stinging catfish larvae have better ability to metabolize lipids. The liver is physiological biomarker because its histological organization is very sensitive to considered reliable nutritional and dietary changes.

Fig.1 Histological sections of stomach and intestine of stinging cat fish larvae at different ages (days post hatch, $\mathrm{dph}$ ). A, general view of stomach of larva from dietary regime, DR- A at $7 \mathrm{dph}$. B, general view of glandular stomach of larva from dietary regime, DR- C at $7 \mathrm{dph}$. C, Histological sections of stomach of larvae from DR D at 7 dph. D, Histological sections of stomach of larvae from DR B at $22 \mathrm{dph}$. E, intestinal sections of mucosa of larva from DR C at $7 \mathrm{dph}$. F, intestinal sections of mucosa of larva from DR G at $7 \mathrm{dph}$. Abbreviations: GG, gastric gland; ME, Mucosal epithelium; NGS, non-glandular stomach. Staining: hematoxylin-eosin

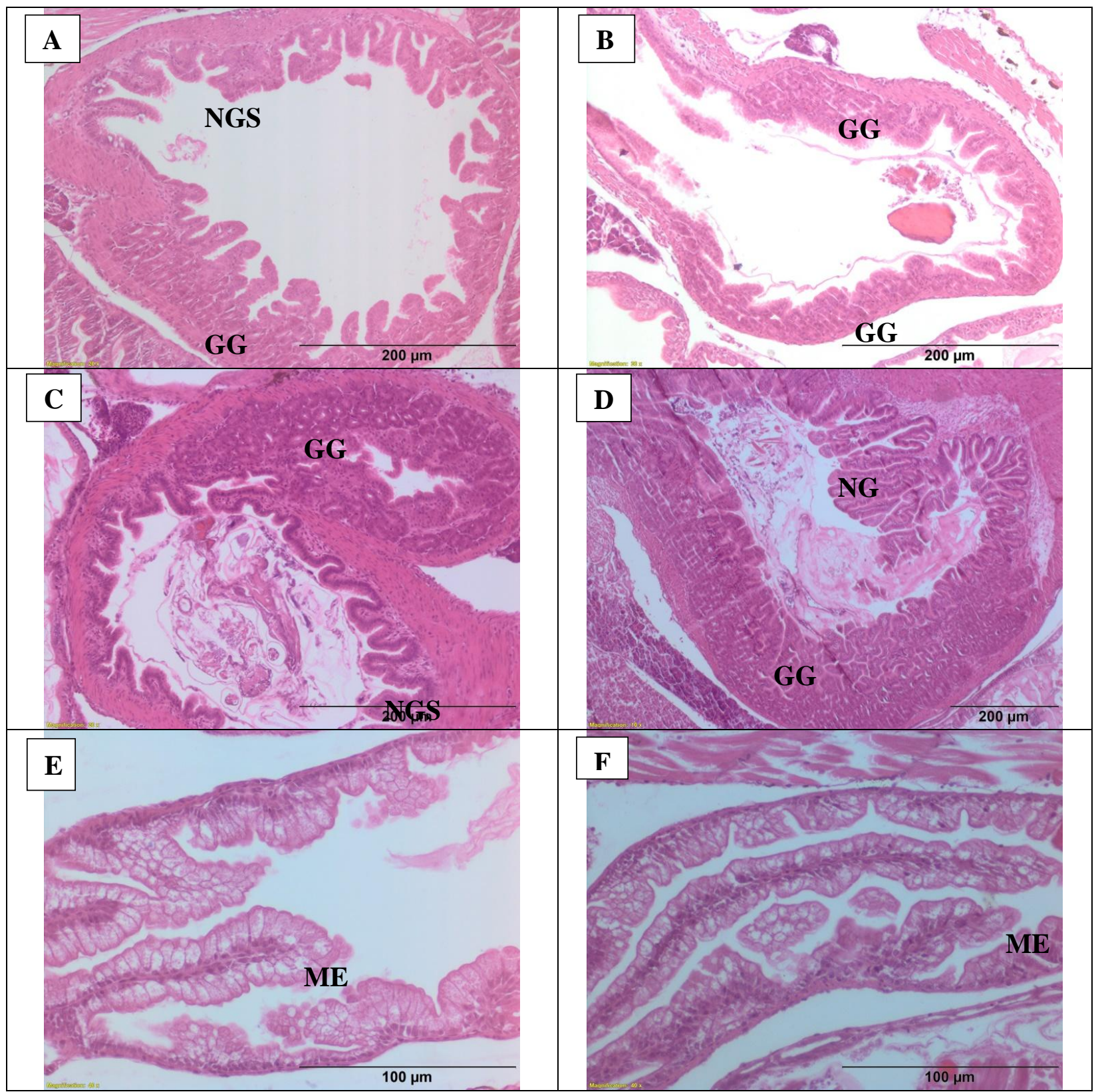


Fig.2 Histological sections of liver and pancreas of stinging catfish larvae at different age. A, section of liver of larvae from DR A at $7 \mathrm{dph}$ showing fat deposits; B, section of liver of larvae from DR D at $7 \mathrm{dph}$ showing fat deposits; C, liver of larvae from DR A at $22 \mathrm{dph}$ showing reduced fat deposits. D, liver of larvae from DR D at 22 dph showing reduced fat deposits; E, Pancreas of larvae from DR A showing zymogen granules in pancreatocyte at $7 \mathrm{dph}$; F, Pancreas of larvae from DR C showing zymogen granules in pancreatocyte at $7 \mathrm{dph}$. Abbreviations: P; pancreatocytes, Z; zymogen granules. Staining: hematoxylin-eosin

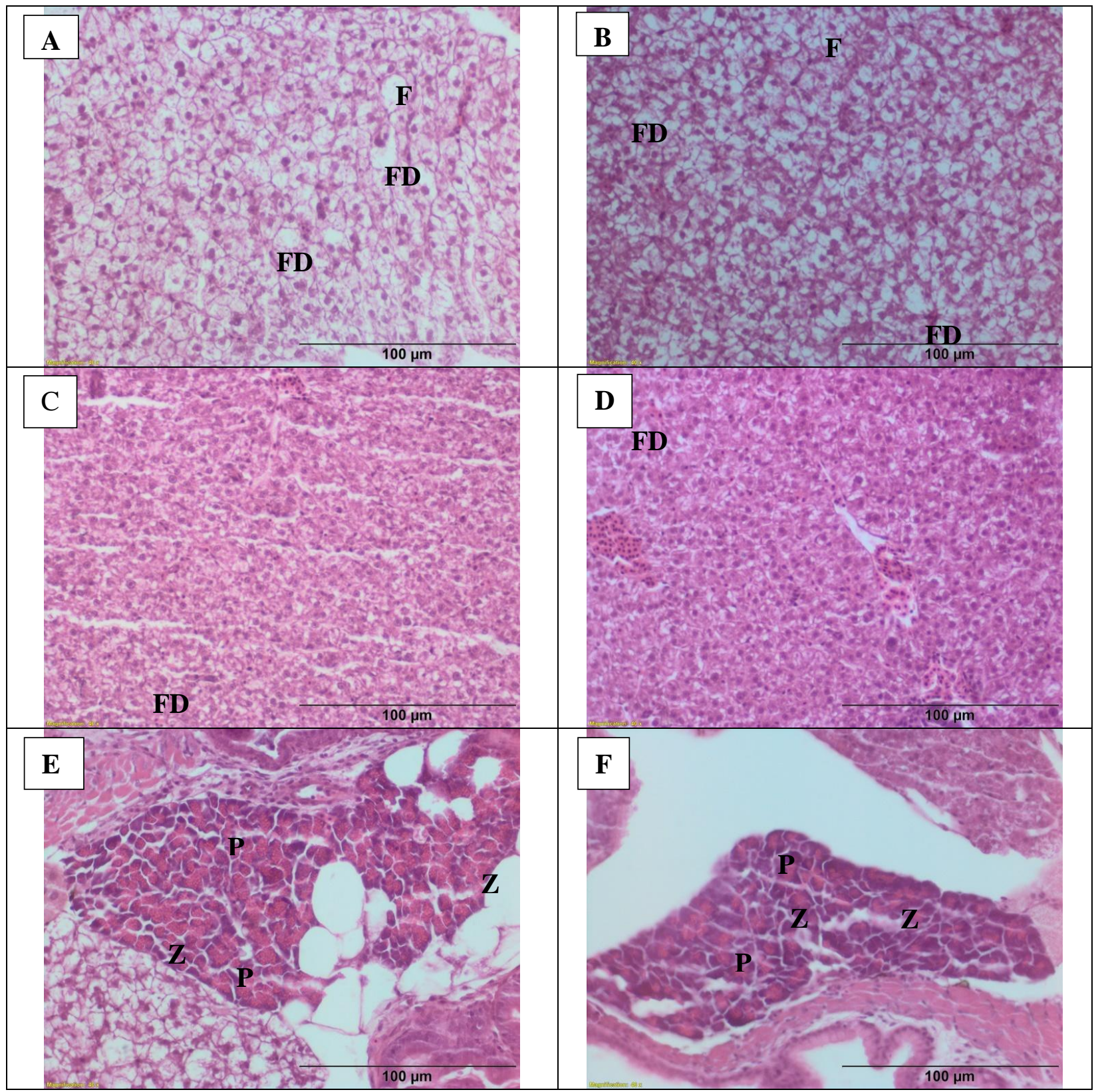

The same trend with regard to the positive correlation between the levels of liver lipid accumulation has been reported by several authors (Boglino et al., 2012; Papadakis et al., 2009, Pradhan et al., 2014), confirming that this organ responds sensitively to changes in the diet in stinging catfish larvae. In the present study, in other dietary regimes (except DR-A and DR-D) in which larvae were fed with mixed zooplankton, microdiet and 
combination of both, showed no/very less level of lipid accumulation in liver, which may be due to the lower total lipid content, a higher proportion of phospholipids and $n-3 / n-$ 6 in comparison to Artemia nauplii (Ahlgren et al., 2009; Øie et al., 2011).

A functional exocrine pancreas is characterized by differentiated organ morphology (acinar gland), including developed excretory ducts and the presence of acidophilic zymogen granules (pancreatic enzyme precursors) (Hoehne-Reitan and Kjørsvik, 2004). This early differentiation and morphogenesis of the exocrine pancreas facilitates its use at a cytological and biochemical level as a good biomarker of the nutritional condition of the larvae. Imbalanced diet induces degeneration of the exocrine pancreas (Yúfera et al., 1993; Crespo et al., 2001). In the present study, exocrine pancreas of stinging catfish larvae fed exclusively with DR-A (Artemia nauplii) and co-fed with Artemia, zooplankton and microdiet (DR-D) had larger pancreocytes arranged in acini and a high amount of zymogen granules, whereas that of larvae fed with other dietary regimes had comparatively smaller pancreocytes and a lesser quantity of zymogen granules. Further, other studies have suggested that in addition to providing some essential micronutrients, Artemia might be contributing to the activation of zymogens or digestive hormones (Petkam and Moodie, 2001) or might be triggering the secretion of endogenous enzymes in comparison to artificial diets and zooplanktons (Pedersen and Hjelmeland, 1988). In addition, it has also been observed that larvae fed with Artemia had higher tryptic activities compared with the weaned larvae in pikeperch Sander lucioperca (Hamza et al., 2007). All these observations support our results, which indicated that the pancreocytes size at $7 \mathrm{dph}$ were comparatively larger in larvae from DRA and DR-D in which Artemia nauplii were offered to larvae in comparison to the rest of dietary treatments (Fig.2 C). The exocrine pancreas in larvae fed DR-C had smaller pancreocytes in comparison to the rest of dietary treatments (Fig. 2D). These differences were also observed at $12 \mathrm{dph}$ and at $17 \mathrm{dph}$. At the end of the study ( $22 \mathrm{dph})$ in all the dietary treatment larvae had abundant zymogen granules and no differences were observed between larvae of different dietary regimes.

Similar to our present findings, Cahu and Zambonino-Infante, (2001) reported that the physiology and morphogenesis of larval digestive tract might be stimulated or impaired, depending on how co-feeding is performed. In addition, the type of microdiet and feeding regime also have been reported to play an important role in the development and maturation of the digestive system (VegaOrellana et al., 2006; Engrola et al., 2007, 2010; Kamarudin et al., 2011; Liu et al., 2012). In this sense, some authors have reported that an improper or abrupt weaning schedule might delay the development of the stomach (Hamza et al., 2007; Liu et al., 2012). In stinging catfish, regardless of the weaning schedule tested, no differences in the level of cellular organization and development were observed among treatments at the end of the study, which indicated high plasticity of this catfish larvae to different nutritional conditions once their digestive system was completely developed and larvae were adapted to the microdiet (Pittman et al., 2013; Rønnestad et al., 2013). Similar to the present study, in shi drum Umbrina cirrosa, Papadakis et al., (2009) also observed lower growth in early weaned larvae without any influence on the timing of the appearance of the various components of the digestive system. Therefore, it can be concluded that it is feasible to rear stinging catfish larvae without dependence upon artemia nauplii, and the larvae may be weaned to microdiets after $7 \mathrm{dph}$. 


\section{Acknowledgements}

The authors are grateful to the Director, ICAR-National Bureau of Fish Genetic Resources, Lucknow and Director, ICARCentral Institute of Fisheries Education, Mumbai for the continuous guidance and encouragement to carry out the research work.

\section{References}

Ahlgren, G., Vrede, T. and Goedkoop, W. 2009. Fatty acid ratios in freshwater fish, zooplankton and zoobenthos-Are there specific optima? In: Arts, M. T., Brett, M.T., Kainz, M. (Eds.), Lipids in Aquatic Ecosystems. Springer Science + Business Media. pp. 147-178.

Akand, A. M., Hasan, M. R. and Habib, M. B. A. 1991. Utilization of carbohydrate and lipis as dietary energy source by H.fossilis, Heteropneustes fossilis (Bloch). In: De Silva, S.S. (Ed.), Fish Nutrition Research in Asia. Proceedings of the Fourth Asian Fish Nutrition Workshop, Asian Fisheries Society Special Publication, Asian Fish Society. Manila. pp. 93-100.

Boglino, A., Gisbert, E., Darias, M. J., Estevez, A., Andree, K. B., Sarasquete, C., Ortiz- Delgado, J. B. 2012. Isolipidic diets differing in their essential fatty acid profiles affect the deposition of unsaturated neutral lipids in the intestine, liver and vascular system of Senegalese sole larvae and early juveniles. Comparative Biochemistry and Physiology. 162A, 59-70.

Burgess, W.E. 1989. An atlas of freshwater and marine catfishes-A preliminary survey of the Siluriformes. TFH Publications, Neptune City, New Jersey.

Cahu, C., Zambonino-Infante, J. L. 2001. Substitution of live food by formulated diets in marine fish larvae. Aquaculture. 200, 161-180.

Chakraborty, B. K., Nur, N. N. 2012. Growth and yield performance of shingi, Heteropneustes fossilis and koi, Anabas testudineus in Bangladesh under semiintensive culture systems. International Journal of Agricultural Research, Innovation and Technology. 2 (2), 15-24.

Crespo, S., Marín de Mateo, M., Santamaría, C., A., Sala, R., Grau, A. and Pastor, E. 2001. Histopathological observations during larval rearing of common dentex Dentex dentex L. (Sparidae). Aquaculture, 192, 121-132.

Engrola, S., Conceicao, L. E. C., Dias, L., Pereira, R., Ribeiro, L. and Dinis, M. T. 2007. Improving weaning strategies for Senegalese sole: effects of body weight and digestive capacity. Aquaculture Research. 38, 696-707.

Ferron, A. and Leggett, W.C. 1994. An appraisal of condition measures for marine fish larvae. Adv. Mar. Biol., 30, 217-303.

Gisbert, E., Moreira, C., Castro-Ruiz, D., Ozturk, S., Fernandez, C., Gilles, S., Nunez, J., Duponchelle, F., Tello, S., Renno, J.F., Garcia-Davila, C. and Darias, M.J., 2014. Histological development of the digestive system of the Amazonian pimelodid catfish Pseudoplatystoma punctifer. Animal, 8(11), 1765-1776.

Gisbert, E., Ortiz-Delgado, J. B., Sarasquete, C. 2008. Nutritional cellular biomarkers in early life stages of fish. Histology and Histopathology. 23, 15251539.

Gisbert, E., Piedrahita, R.H. and Conklin, D.E. 2004. Effects of delayed first feeding on the nutritional condition and mortality of California halibut larvae. J. Fish Biol., 64, 116-132.

Gisbert, E., Villeneuve, L., Zambonino Infante, J.L., Quazuguel, P. and Cahu, C.L. 2005. Dietary phospholipids are more efficient than neutral lipids for long-chain polyunsaturated fatty acid supply in European sea bass Dicentrarchus labrax larval development. Lipids 40, 1-11.

Hamza, N., Mhetli, M. and Kestemont, P. 2007. Effects of weaning age and diets on ontogeny of digestive activities and structures of pikeperch (Sander lucioperca) larvae. Fish Physiol. Biochem., 33, 121-133.

Hoehne-Reitan, K. and Kjørsvik, E. 2004. Functional development of the liver and exocrine pancreas. Am. Fish. Soc., 40, 9-36.

Jones, D. A., Kamarudin, M. S., Le Vay, L. 1993. The potential for replacement of live feeds in larval culture. Journal of the World Aquaculture Society. 24: 199-209.

Kamarudin, M. S., Otoi, S., Saad, C. R. 2011. Changes in growth, survival and digestive enzyme activities of Asian redtail catfish, Mystus nemurus, larvae fed on different diets. African Journal of Biotechnology. 10, 4484-4493.

Khojasteh, S.M.B. 2012. The morphology of the postgastric alimentary canal in teleost fishes: a brief review. Int. J. Aquac. Sci., 3, 71-88.

Kjorsvik, E., van der Meeren, T.M., Kryvi, H., Arnfinnson, J., and Kvenseth, P.G. 1991. Early development of the digestive tract of cod larvae, Gadus morhua L., during start-feeding and starvation. J. Fish Biol., 38: 1-15.

Koven, W., Kolkovski, S., Hadas, E. Gamsiz, K., Tandler, A. 2001. Advances in the development of microdiets for gilthead seabream, Sparus aurata: a review. Aquaculture. 194: 107-121 
Langdon, C., Barrows, R. 2011. Microparticulate diets: technology. In: Holt, G.J. (Ed.), Larval Fish Nutrition. Wiley-Blackwell, Oxford, UK, pp. 335351.

Lazo, J. P., Darias, M. J. and Gisbert, E. 2011. Ontogeny of the digestive tract. In: Holt, G.J. (Ed.), Larval Fish Nutrition. Wiley-Blackwell, Oxford, UK, pp. 5-46.

Liu, B., Zhu, X., Lei, W., Yang, Y., Han, D., Jin, J., Xie, S. 2012. Effects of different weaning strategies on survival and growth in Chinese longsnout catfish (Leiocassis longirostris Gunther) larvae. Aquaculture. 364-365, 13-18.

NBFGR, 2011. Proceedings of National Consultation on Species Prioritization for Ex situ Conservation and Freshwater Aquaculture, 17-18 September 2011. NBFGR, Lucknow 22.

Øie, G., Reinta, K. I., Evjemo, J. O., Støttrup, J., Olsen, Y. 2011. Live feeds. In: Holt, G.J. (Ed.), Larval Fish Nutrition. Wiley-Blackwell, Oxford, UK, pp. 307-334.

Papadakis, I. E., Zaiss, M. M., Kyriakou, Y., Georgiou, G., Divanach, P., Mylonas, C. C., 2009. Histological evaluation of the elimination of Artemia nauplii from larval rearing protocols on the digestive system ontogeny of shi drum (Umbrina cirrosa L.). Aquaculture. 253, 334-342.

Pedersen, B.H. and Hjelmeland, K. 1988. Fate of trypsin and assimilation efficiency in larval herring Clupea harengus following digestion of copepods. Mar. Biol., 97, 467-476.

Person-Le Ruyet, J., Alexandre, J. C., Thebaud, L., Mugnier, C. 1993. Marine fish larvae feeding: formulated diets or live prey? Journal of the World Aquaculture Society. 24, 211-224.

Petkam, R. and Moodie, G.E.E. 2001. Food particle size, feeding frequency, and the use of prepared food to culture larval walking catfish, Clarias macrocephalus. Aquaculture, 194, 349-362.

Pittman, K., Yufera, M., Pavlidis, M., Geffen, A.J., Koven,W., Ribeiro, L., Zambonino-Infante, J.L. and Tandler, A. 2013. Fantastically plastic: fish larvae equipped for a new world. Rev. Aquacult., 5, S224-S267.

Pradhan, P. K., Jena, J. K., Mitra, G., Sood, N., Gisbert, E. 2014. Effects of different weaning strategies on survival, growth and digestive system development in butter catfish Ompok bimaculatus (Bloch) larvae. Aquaculture, 424-425, 120-130.

Puvaneswari, S., Marimuthu, K., Karuppasamy, R., Haniffa, M. A. 2009. Early embryonic and larval development of Indian catfish, Heteropneustes fossilis. EurAsian Journal of BioSciences. 3, 84-96.

Rønnestad, I., Yufera, M., Ueberschar, B., Ribeiro, L., Saele, O. and Boglione, C. 2013. Feeding behaviour and digestive physiology in larval fish: current knowledge, and gaps and bottlenecks in research. Rev. Aquacult., 5, S59-S98.

Segner, H., Rösch, R., Verreth, J. and Witt, U., 1993. Larval nutritional physiology: studies with Clarias gariepinus, Coregonus lavaretus and Scophthalmus maximus. J. World Aquacult. Soc., 24, 121-134.

Silveira, J., Silva, C.P., Cargnin-Ferreira, E., Alexandre, D., Elias, M.A., and Fracalossi, D.M. 2013. Freshwater catfish jundia (Rhamdia quelen) larvae are prepared to digest inert feed at the exogenous feeding onset: physiological and histological assessments. Fish Physiol. Biochem., 39, 1581-1590.

Vega-Orellana, O. M., Fracalossi, D. M., Sugai, J. K. 2006. Dourado (Salminus brasiliensis) larviculture: weaning and ontogenetic development of digestive proteinases. Aquaculture. 252, 484-493.

Verreth, J. and Tongeren, M.V. 1989. Weaning time in Clarias gariepinus (Burchell) larvae. Aquaculture, 83, 81-88.

Vijayakumar, C., Sridhar, S. and Haniffa, M. A. 1998. Low cost breeding and hatching techniques of the catfish (Heteropneustes fossilis) for small-scale farmers. Naga, the ICLARM Quarterly 21, 15-17.

Watanabe, T., Kiron, V. 1994. Prospects in Larval Fish Dietetics. Aquaculture. 124: 223-251.

Yufera M., Pascual, E., Polo, A. and Sarasquete, M.C. 1993. Effect of starvation on the feeding ability of gilthead seabream (Sparus aurata L.) larvae at first feeding. J. Exp. Mar. Biol. Ecol., 169, 259-272.

Zambonino-Infante, J., Gisbert, E., Sarasquete, C., Navarro, I., Gutiérrez, J. and Cahu, C.L., 2008. Ontogeny and physiology of the digestive system of marine fish larvae. In: Feeding and digestive functions of fish. Cyrino J.E.O., Bureau D. and Kapoor B.G. (eds). Science Publishers. Inc, Enfield, USA pp 277-344.

\section{How to cite this article:}

Aditya Kumar, P. K. Pradhan, N. K. Chadha, V. Mohindra, V. K. Tiwari and Sood N. 2018. Effect of Dietary Regimes on Development of Digestive System of Stinging Catfish, Heteropneustes fossilis (Bloch) Larvae. Int.J.Curr.Microbiol.App.Sci. 7(08): 413-421. doi: https://doi.org/10.20546/ijcmas.2018.708.047 